\title{
Venturimetre Deneyinde Gerçek ve Teorik Debi İlişkisi İçin Debi Düzeltme Katsayısının Belirlenmesi
}

\author{
Halil İbrahim Burgan ${ }^{1 *}$ \\ 1 İstanbul Kültür Üniversitesi, Mühendislik Fakültesi, İnşaat Mühendisliği Bölümü, İstanbul, Türkiye (ORCID: 0000-0001-6018-3521)
}

(Illk Geliş Tarihi 03 Ocak 2020 ve Kabul Tarihi 22 Şubat 2020)

(DOI: $10.31590 /$ ejosat.669941)

ATIF/REFERENCE: Burgan, H. İ. (2020). Venturimetre Deneyinde Gerçek ve Teorik Debi İlişkisi İçin Debi Düzeltme Katsayısının Belirlenmesi. Avrupa Bilim ve Teknoloji Dergisi, (18), 91-98.

$\ddot{O} \mathbf{z}$

Akışkanlar mekaniğinde basınçlı borularda kesitten geçen debinin hesaplanması her zaman pratik olmamaktadır. Bu nedenle deneysel yöntemlerle elde edilen denklemler yaygın bir şekilde kullanılmaktadır. Bu çalışmada venturimetre deney setinde ölçülen gerçek debi ile süreklilik ve Bernoulli denklemleri kullanılarak hesaplanan teorik debi karşılaştırılmıştır. Literatürde teorik debiyi gerçek debi olarak kullanabilmek için debi düzeltme katsayısından $\left(\mathrm{C}_{\mathrm{d}}\right)$ yararlanılmaktadır. Bunun nedeni teorik debi hesabında sürekli ve yersek yük kayıplarının dikkate alınmamasıdır. Debi düzeltme katsayısı 0.8-1.0 aralı̆ı̆ında önerilmektedir. Gerçek debinin teorik debiye bölünmesi ile $C_{d}$ katsayısı elde edilir. Diğer bir ifadeyle teorik debinin formülüne $C_{d}$ katsayısının eklenmesi ile akışkanın gerçek debisi bulunur. Boruda meydana gelen akımda sürekli ve yersel yük kayıpları deneysel olarak hesaplanmaktadır. Sürekli yük kayıpları için Darcy-Weisbach eşitliği ve yersel yük kayıpları için de kayıp katsayıları kullanılmaktadır. Borudaki akımın yük kayıplarını hesaplamak her zaman pratik olmamaktadır. Bu nedenle hassas sonuçların gerekmediği pratik olarak debi hesabı durumlarında debi düzeltme katsayısı tercih edilmektedir.

$\mathrm{Bu}$ çalışmada venturimetre deneyinde gerçek debi için altı farklı gözlem yapılmıştır. Öncelikle deney setine maksimum debiler verilmiş, daha sonra vana yardımıyla debi azaltılmıştır. Boru içerisindeki akışkan olarak su seçilmiştir. Debi ölçümü için hazneye su doldurularak birim zamanda biriken su hacmi hesaplanmıştır. Elde edilen bulgulara göre debi düzeltme katsayısı daha dar bir aralık 0.939-0.975 olarak elde edilmiştir. Ayrıca debi düzeltme katsayısı ve teorik debi arasında güçlü bir ilişsi gözlenmiştir. Bu amaçla determinasyon katsayısı $\left(\mathrm{R}^{2}\right)$ hesaplanmıştır. Bu sayede boru içerisindeki akım için akışkan su seçilmiş ve debi düzeltme katsayısı bu tip çalışmalar için revize edilmiştir. Gelecekteki çalışmalarda süt, yağ gibi viskozitesi daha yüksek akışkanlar kullanılarak debi düzeltme katsayıları incelenebilecektir.

\section{The Determination of Discharge Coefficient for the Relationship between Real and Theoretical Dicharge in Venturimeter Experiment}

\begin{abstract}
It is not always practical to calculate the discharge through the pressure pipes in fluid mechanics. Therefore, empirical equations obtained by experimental methods are widely used. Real discharge measured in the venturimeter experiment is compared with theoretical discharge calculated using the continuity and Bernoulli equations in this study. Discharge coefficient $\left(\mathrm{C}_{\mathrm{d}}\right)$ is used in order to use theoretical discharge as real discharge in the literature. The reason for this is that the major and minor head losses are not taken
\end{abstract}

* Sorumlu Yazar: İstanbul Kültür Üniversitesi, Mühendislik Fakültesi, İnşaat Mühendisliği Bölümü, İstanbul, Türkiye, ORCID: 0000-0001-60183521, h.burgan@iku.edu.tr 
into account in theoretical discharge calculation. Discharge coefficient is recommended in the range of $0.8-1.0$. $\mathrm{C}_{\mathrm{d}}$ coefficient is obtained by dividing the real discharge by theoretical discharge. In other words, real discharge of the fluid is found by adding $\mathrm{C}_{\mathrm{d}}$ coefficient to the formula of theoretical discharge. Major and minor head losses in flow occurring in the pipe are calculated empirically. Darcy-Weisbach equation is used for major head losses and loss coefficients are used for minor head losses. It is not always practical to calculate head losses of flow in the pipe. Consequently, discharge coefficient is preferred in cases where discharge calculation is practically not required.

Six different observations are made for real discharge in venturimeter experiment in this study. Firstly, maximum discharges are given to the experiment set and then discharge is reduced with the help of the valve. Water is selected as the fluid in the pipe. The volume of water accumulated per unit time is calculated by filling the reservoir with water for dischage measurement. According to the findings, the discharge coefficient is obtained as a narrower range 0.939-0.975. In addition, a strong relationship between the discharge coefficient and theoretical discharge is observed. For this purpose, the determination coefficient $\left(\mathrm{R}^{2}\right)$ is calculated. Thus, fluid water is selected for the flow in the pipe and the discharge coefficient is revised for this type of work. Discharge coefficients can be examined by using higher viscosity fluids such as milk and oil for future studies.

Keywords: Bernoulli equation, Discharge coefficient, Real discharge, Theoretical discharge, Venturimeter.

\section{Giriş}

Venturimetre ve orifismetre gibi ölçüm teknikleri basınçlı bir boru akımında debi ölçümüne imkan sağlamaktadır. Bu tekniklerde kullanılan deney düzeneği, herhangi şekil ve boyuttaki boru hattına kurularak ele alınan kesitlerdeki basınç farkları yardımıyla debi hesaplanabilir. Venturimetreden geçen akış, geniş ve dar kesit arasında bir basınç farkına yol açarken orifismetrede memba kesiti ile daralan akış kesiti arasında bir basınç farkı vardır. Bernoulli denkleminde elde edilen basınç farkı kullanılarak boru kesitindeki debi hesaplanır. Bu debiölçerlerin hareketli parçası olmadığından kolay aşınma ve yıpranma gözlenmez (Swamee 2005). Venturimetre, anlık debiyi göstermekle beraber debinin entegrasyonu da elde edilebilir. Venturimetrede debinin hesaplanması amacıyla akımın karakteristiğini ortaya koyan Reynolds $(\mathrm{Re})$ sayısına bağlı debi düzeltme katsayısının $\left(\mathrm{C}_{\mathrm{d}}\right)$ belirlenmesi gereklidir. Venturimetreye ait şematik gösterim Şekil 1'de sunulmaktadır.

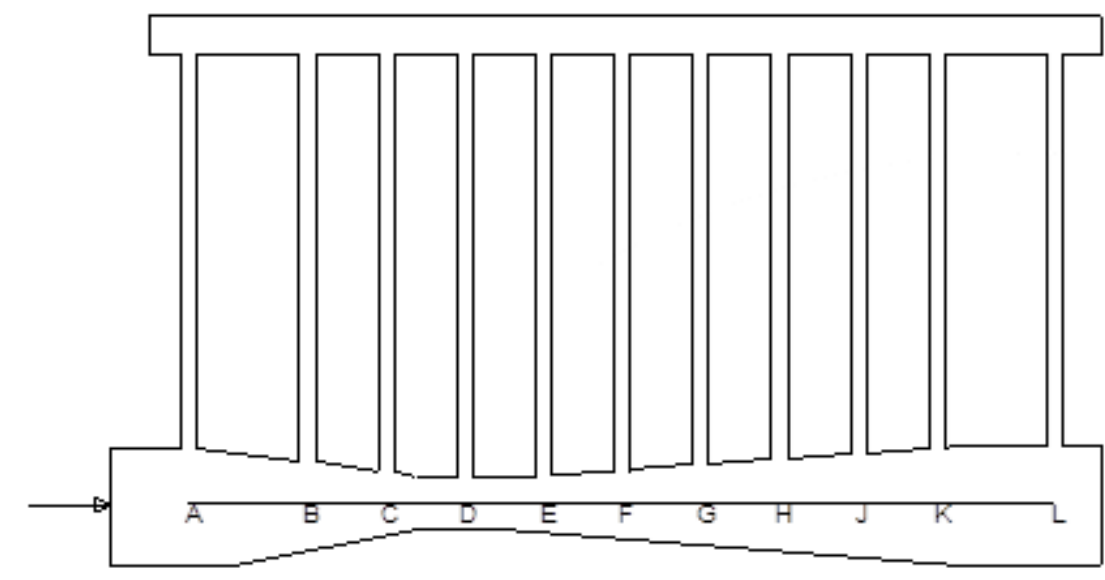

Şekil 1. Venturimetrenin şematik gösterimi.

Diğer tüm basınç farkı ölçen cihazlar gibi sıvı ve gaz akışının gerçekleştiği basınçlı boru akımında venturimetrede ölçülen değerler sıvı varlığından dolayı olumsuz etkilenir. Yani sıvının varlığı, venturimetre tarafından memba kesiti ve daralan kesit arasındaki okunan basınç farkını doğrudan etkiler (Steven 2002). Bu nedenle literatürde, akım hızını doğru bir şekilde elde etmek için gözlenen debi değerine bir düzeltme uygulanması önerilmektedir.

Venturimetrenin ilk kullanımı 1800’lü yıllara dayanmaktadır. Basınçlı boruda doğru debinin ölçüm zorlukları nedeniyle, debinin teorik olarak hesaplanması tercih edilir. Bu konuda yapılan deneyler neticesinde ilk pratik uygulama Clemens Herschel tarafından yapılmış ve deney düzeneğinin adı aletin teorisini geliştiren Giovanni Batista Venturi’ye dayanarak Venturimetre olarak kullanılmıştır. Herschel-konik tip ölçüm cihazında elde edilen sonuçlarda gözlenen ve hesaplanan debi değerleri arasında fark olmakla birlikte aralarında pozitif bir ilişki gözlenmiştir (Hutton 1954). Debi düzeltme katsayısı $\left(C_{d}\right)$ bire yakın olup borudaki basınç kaybının memba kesiti ile daralan kesit arasındaki basınç farkına oranı genellikle 0.05-0.25 aralı̆̆ındadır (Harris 2015).

Venturimetrelerin çok geniş ve yaygın kullanım alanları bulunmaktadır. Başta inşaat, kimya, makine ve uçak mühendisliği olmak üzere birçok mühendislik alanında ve enerji, tıp gibi diğer alanlarda kullanılmaktadır. Özellikle akışkanlar mekaniğinde süreklilik ve Bernoulli denklemlerine dayalı venturimetreler, su jeti pompası ve dip tarama problemlerinde (Yeşilmen ve Göğüş 2004), dalgıç pompa performans testlerinde (Korkmaz ve ark. 2009), su alma borusunun tabandan olan mesafesinin tayininde (Kocabaş ve Ülker 2004), tesisat hataları nedeniyle yaşanan debi ölçüm sorunlarında (Akyol ve ark. 2011), damarda kan debisinin ölçülmesinde (Wagoner ve Livingston 1928), yaş-gaz akışının modellenmesinde ele alınmıştır (Xu ve ark. 2011).

Venturimetre deney düzeneğinde hem sıvıların hem de gazların akışkan olarak kullanıldığı bilinmektedir. Çeşitli disiplinlerde kullanımı bulunan venturimetrenin güncel kullanımı enerji, 1sı ve kütle transferi gibi konulardadır. Bu kapsamda dairesel düşey kesitte 
gerçekleşen gaz akışı için basınç düşmesi Venturimetre yardımıyla hesaplanabilmiştir (Wang ve ark. 2020). Ayrıca çalışmada elde edilen deneysel sonuçların \%98.5 güven düzeyinde $\% 10$ rölatif hata sınırları içerisinde kaldığı gözlenmiştir. Diğer bir çalışmada, yeni tip pürüzlülük elemanının Havacılık Ulusal Danışma Komitesi (NACA) 0040 ters yerleştirilmiş profil kanatlarına güneş enerjili hava ısıtıcısının performansı incelenmiștir. Rölatif pürüzlülük alanı ve rölatif pürüzlülük yüksekliğinin etkileri, Reynolds (Re) sayısının 6000 - 18000 olduğu aralıkta araştırılmıştır. Hava akımının ölçümünde venturimetre deney düzeneği kullanılmıştır. Deneysel ve sayısal yöntemler karşılaştıııldığında rölatif pürüzlülük yüksekliği ve Re sayısının $\pm \% 3$ hata payına sahip olduğu belirlenmiştir (Patel ve ark. 2020). Venturimetre sayesinde gerçekleştirilen kapsamlı ve detaylı uygulamaların yanında yukarıda belirtilen mühendislik programları akışkanlar mekaniği temel dersinde Bernoulli ve enerji denklemlerinin deneysel ve sayısal uygulamaları yapilabilmektedir (Mandavgane 2020).

$\mathrm{Bu}$ çalışmada, teorik olarak elde edilen debi değerleri debi düzeltme katsayısı $\left(\mathrm{C}_{\mathrm{d}}\right)$ arasındaki ilişki incelenmiş̧ir. Bu kapsamda bire yakın çıkması beklenen $C_{d}$ katsayısı için daha dar bir aralık sunulmuştur. Ayrıca akışkan olarak su belirlenmiş ve elde edilen doğrusal ilişki için bir denklem önerilmiştir. Sonuçların değerlendirilmesi amacıyla da determinasyon katsayısı $\left(\mathrm{R}^{2}\right)$ hesaplanmıştır.

\section{Materyal ve Metot}

\subsection{Venturimetre deney düzeneği}

Venturimetre, daralan ve genişleyen akış bölgesine sahip boru ve kanallarda akış hızını ölçerek boru içinden geçen debinin ölçülmesinde kullanılmaktadır. Venturimetre, basınçlı bir boru devresine bağlanmıştır (Şekil 2). Kütlesel ve hacimsel debi, pompa hızınının değişmediği durumda sistem kapalı olduğu için sabittir. Sistem, süreklilik ve Bernoulli denklemleri esasına göre çalı̧̧maktadır.

Boru içinde akan akışkan tedricen daralan bir kesit boyunca mansap tarafindaki daha küçük çaplı bir kesitten geçerken, dar kesit içindeki akımın hızı, memba kesitindeki akım hızından daha büyük olur. Bu hız artışıla birlikte basınçta düşüş görülür. Böylece basınç değişimi ölçülerek akışkanın debisi hesaplanabilir. Dar kesitin mansap tarafında akım hızı azalır ve hız düşerken basınç artar. Venturimetre boyunca 11 noktada (Şekil 1, A-L noktaları) basınç ölçümü için manometre (piyezometre) tüpleri bağlanmıştır.

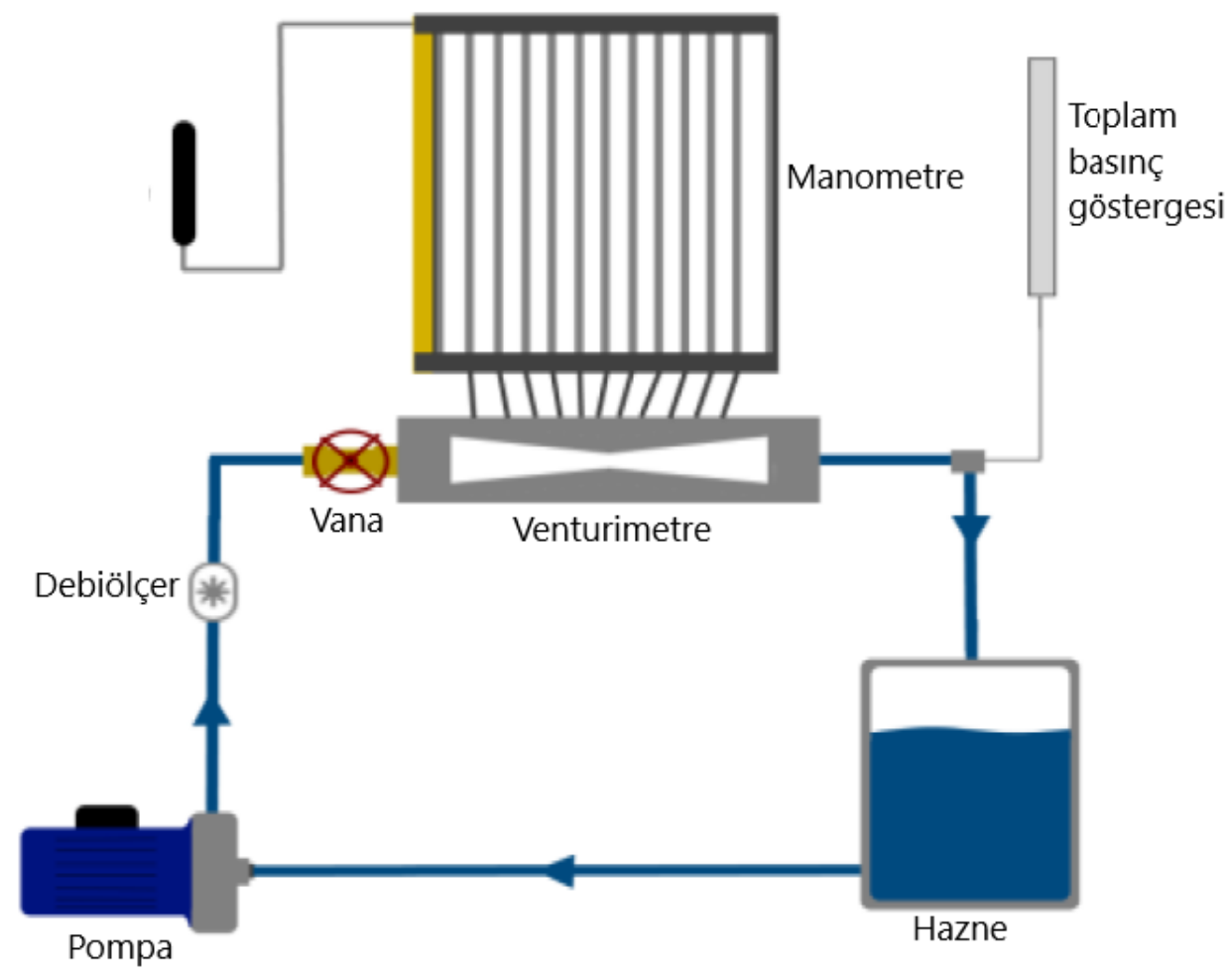

Şekil 2. Venturimetre deney düzeneği (OGEN 2014a).

\subsection{Teorik debinin hesaplanması}

Bir akım çizgisi boyunca daimi, sürtünmesiz, sıkıştırılamaz akış için herhangi iki farklı kesitte Bernoulli denklemi aşağıdaki gibidir. Bernoulli denklemi sürtünmesiz bir akışta kesitsel ortalama akım hızı, basınç ve kot farkı arasındaki ilişkiyi verir.

$$
\frac{\mathrm{V}_{1}{ }^{2}}{2 \mathrm{~g}}+\frac{\mathrm{p}_{1}}{\gamma}+\mathrm{z}_{1}=\frac{\mathrm{V}_{2}{ }^{2}}{2 \mathrm{~g}}+\frac{\mathrm{p}_{2}}{\gamma}+\mathrm{z}_{2}
$$


Yatay bir sistem $\left(\mathrm{z}_{1}=\mathrm{z}_{2}\right)$ için Bernoulli denklemi,

$$
\frac{\mathrm{V}_{1}^{2}}{2 \mathrm{~g}}+\frac{\mathrm{p}_{1}}{\gamma}=\frac{\mathrm{V}_{2}^{2}}{2 \mathrm{~g}}+\frac{\mathrm{p}_{2}}{\gamma}
$$

(2) denklemi yeniden düzenlendiğinde,

$$
\frac{\mathrm{V}_{2}{ }^{2}-\mathrm{V}_{1}{ }^{2}}{2 \mathrm{~g}}=\frac{\mathrm{p}_{1}-\mathrm{p}_{2}}{\gamma}=\mathrm{h}_{\mathrm{p}}
$$

haline dönüşür. Burada $h_{p}$ basınç farkı yüksekliğini vermektedir. $V_{2}{ }^{2}$ ifadesi denklemin sol tarafına çekildiğinde,

$$
\mathrm{V}_{2}^{2}=2 \mathrm{gh}_{\mathrm{p}}+\mathrm{V}_{1}^{2}
$$

Akımın süreklilik denklemi,

$$
\mathrm{V}_{1} \mathrm{~A}_{1}=\mathrm{V}_{2} \mathrm{~A}_{2}=\mathrm{Q}
$$

$\mathrm{V}_{1}$ hızı çekildiğinde,

$$
\mathrm{V}_{1}=\mathrm{V}_{2} \frac{\mathrm{A}_{2}}{\mathrm{~A}_{1}}
$$

$\mathrm{V}_{1}$ akım hızı (4) denkleminde yerine konulduğunda,

$$
\mathrm{V}_{2}{ }^{2}=2 \mathrm{gh}_{\mathrm{p}}+\left(\mathrm{V}_{2} \frac{\mathrm{A}_{2}}{\mathrm{~A}_{1}}\right)^{2}
$$

(7) denklemi yeniden düzenlendiğinde

$$
\mathrm{V}_{2}^{2}\left(1-\left(\frac{\mathrm{A}_{2}}{\mathrm{~A}_{1}}\right)^{2}\right)=2 \mathrm{gh}_{\mathrm{p}}
$$

$\mathrm{V}_{2}$ hizı,

$$
V_{2}=\sqrt{\frac{2 g h_{p}}{1-\left(\frac{A_{2}}{A_{1}}\right)^{2}}}
$$

Sistemin teorik debisi ise süreklilik deninleminden (5),

$$
Q_{\text {teorik }}=A_{2} \sqrt{\frac{2 g h_{p}}{1-\left(\frac{A_{2}}{A_{1}}\right)^{2}}}
$$

hesaplanır. Gerçek debiyi hesaplayabilmek için teorik debinin debi düzeltme katsayısı $\left(\mathrm{C}_{\mathrm{d}}\right)$ ile çarpılması gerekmektedir. Bu çalışmada debi düzeltme katsayısı $\left(\mathrm{C}_{\mathrm{d}}\right)$,

$$
C_{d}=\frac{Q_{\text {gerçek }}}{Q_{\text {teorik }}}
$$

denklemiyle elde edilmiştir.

\subsection{Gerçek debinin hesaplanması}

Venturimetre deney düzeneğinde gerçek debi $\left(Q_{\text {gerceek }}\right)$ Şekil 2'deki debimetre yardımıyla ölçülebilmektedir. Debimetreler basınçlı boru akımlarında debi ölçümlerinde kullanılmaktadır. Debimetre, yukarıya doğru konik olarak genişleyen şamandıralı bir 
cihaz olup şamandıra hareketiyle okuma yapılabilecek bir göstergesi bulunmaktadır (Şekil 3). Çalışma prensibi debiye bağlı olup akım hızı yani debi arttığında şamandıra yukarıya doğru hareket ederek şamandıra üst kotuna karşı gelen göstergedeki değer deneyden ölçülen gerçek debi değeridir. Debimetreler akışkan debisinin belirlenmesinde yaygın bir şekilde kullanılmaktadır. Aynı zamanda vana yardımıyla akışkanın debisi ayarlanabilmektedir (Yılancı ve ark. 2019).

Bununla birlikte debimetrenin bulunmadığı durumlarda gerçek debinin ölçülmesi için hazne ve süreölçer yeterli olmaktadır. Pompa yardımıyla basınçlı boruya su iletilirken pompanın su aldığı hazne kapatılarak süreölçer başlatılır. Hazne içerisindeki belirli bir hacim ya da seviye gösterge çizgisine kadar su doldurulduğunda süreölçer durdurularak hacim/zaman oranından debi kolayca bulunabilir. Her iki sistemde de debinin ayarlanabilmesi için vana bulunmaktadır.

Sistemin debisinin belirlenmesinde diğer bir yöntem olarak da ölçme savakları kullanılmaktadır. Burada haznede biriktirilen akışkan, savak üzerinden geçirilir. Savağın tipine göre (üçgen, keskin kenarlı, dikdörtgen) savak yüksekliği ölçülür. Savak yüksekliği ve savağın ağız açısına bağlı olarak sistemin debisi deneysel olarak elde edilebilir.

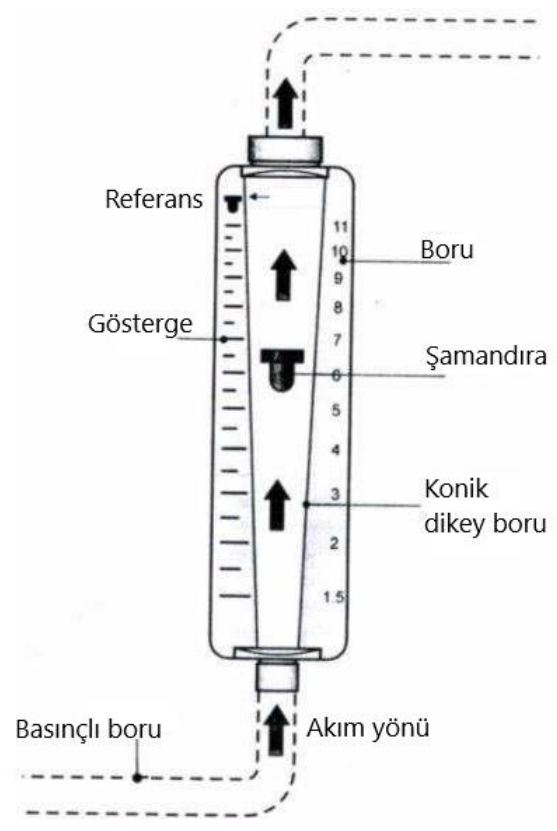

Şekil 3. Debi ölçümünde kullanılan debimetrenin temsili gösterimi (OGEN 2014b).

A-L noktaları arasında herhangi iki nokta için Bernoulli ve süreklilik denklemleri yazılarak seçilen noktalarda ölçülen basınç yükseklikleri farkıyla debi hesaplanabilir. Süreklilik denklemiyle gözlenen kesitteki hız değerini bulmak amacıyla gözlenen kesit alanları hesaplanırken Tablo 1'de yer alan çap değerleri kullanılmıştır.

Tablo 1. Çalışmada kullanılan venturimetre gözlem noktalarına ait kesitteki çap değerleri

\begin{tabular}{c|c}
\hline Kesit numarası & Çap (mm) \\
\hline $1(\mathrm{~A})$ & 26.00 \\
\hline $2(\mathrm{~B})$ & 23.20 \\
\hline $3(\mathrm{C})$ & 18.40 \\
\hline $4(\mathrm{D})$ & 16.00 \\
\hline $5(\mathrm{E})$ & 16.80 \\
\hline $6(\mathrm{~F})$ & 18.47 \\
\hline $7(\mathrm{G})$ & 20.16 \\
\hline $8(\mathrm{H})$ & 21.84 \\
\hline $9(\mathrm{~J})$ & 23.53 \\
\hline $10(\mathrm{~K})$ & 25.24 \\
\hline $11(\mathrm{~L})$ & 26.00 \\
\hline
\end{tabular}

Venturimetrede gözlem yapılan gözlem noktaları arasında belirli bir mesafe bulunmalıdır. Gözlem yapılan kesitler arasındaki mesafeler Şekil 4’te sunulmaktadır. Ayarlanan tüm piyezometre tüplerinin okumaları yapılarak venturimetre boyunca basınç dağılımı bu sayede belirlenmiş olur. Basınçlı boru sisteminde basınç yüksekliklerinin doğru bir şekilde okunabilmesi amacıyla hava kabarcığı bulunmamasina dikkat edilir. 


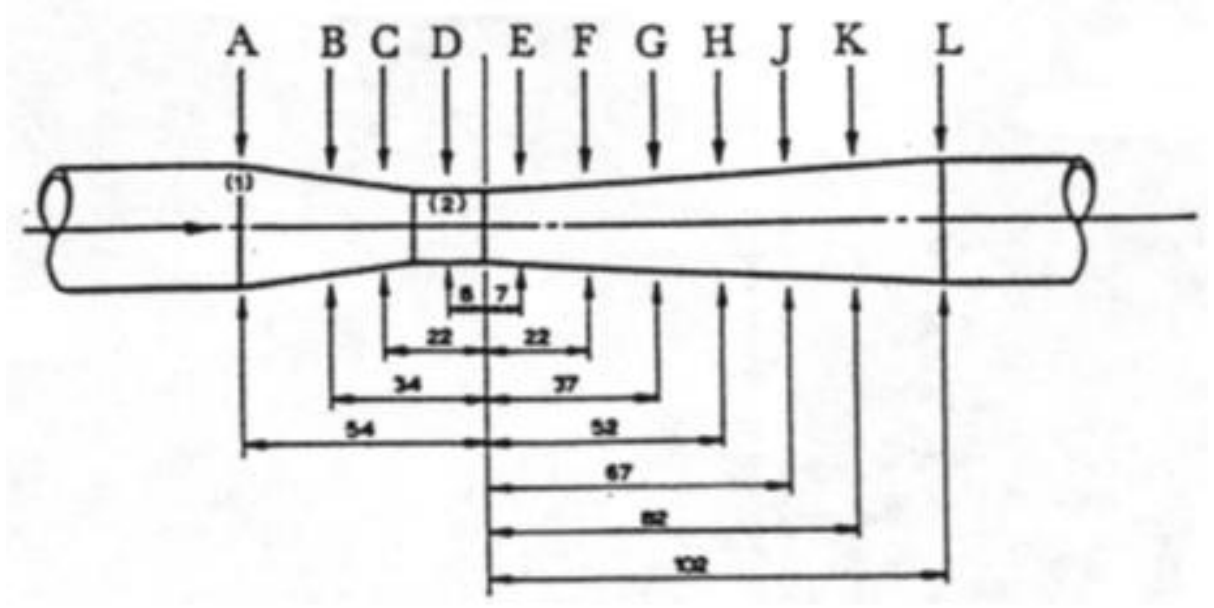

Şekil 4. Piyezometre seviyelerinin ölçümünde kullanılan gözlem noktalarının mesafeleri (mm).

\section{Araştırma Sonuçları ve Tartışma}

Yapılan deneyler sonucunda A-L gözlem kesitlerine bağlı piyezometre tüplerinde bulunan su seviyeleri ölçülerek basınç yükseklikleri belirlenmiştir (Şekil 5). Bu sayede ele alınan memba kesiti (A noktası) ile en dar kesit (D noktası) arasında gerekli hesaplar yapılmıştır. Hesaplanan debi, süreklilik ve Bernoulli denklemlerinde kullanılarak kesitlerdeki hız değerleri elde edilmiştir.

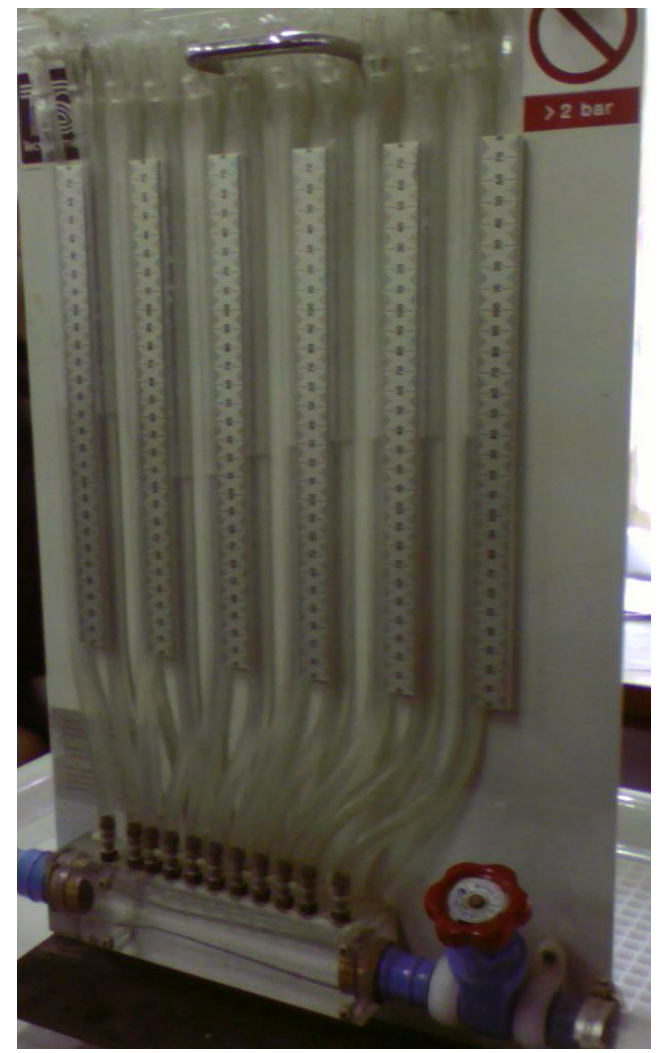

Şekil 5.Deneyde kullanılan venturimetre deney düzeneği ve piyezometre tüpleri.

Deneyde ölçülen ve teorik olarak hesaplanan piyezometre çizgileri Şekil 6'dadır. Piyezometre tüplerinin başlangıç noktasına olan mesafeleri dikkate alınarak venturimetre boyunca ölçülmüş olan basınç değerleri ile ideal basınç değerleri aynı grafik üzerinde çizilmiştir. $\left(h_{n}-h_{1}\right) /\left(V_{2}^{2} / 2 g\right)$ ile ifade edilen piyezometre çizgileri ölçülen basınç değerlerini ve $\left(V_{1} / V_{2}\right)^{2}-\left(V_{n} / V_{2}\right)^{2}$ ile ifade edilen piyezometre çizgileri ise hesaplanan ideal basınç değerlerini ifade etmektedir. 


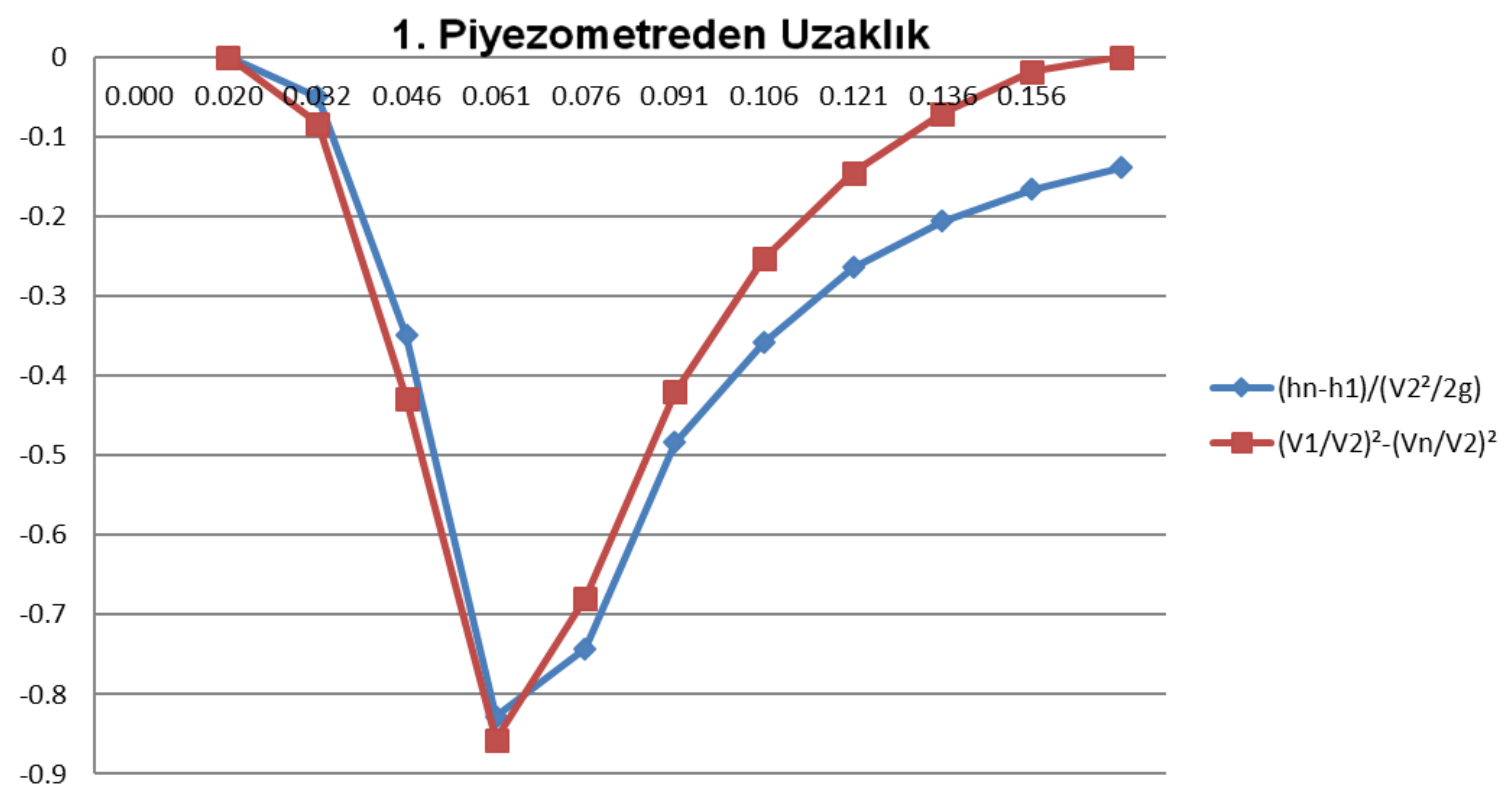

Şekil 6. Teorik ve deneysel piyezometre çizgileri.

Çalışmada, debi düzeltme katsayısı $\left(C_{d}\right)$ denklem (11) ile elde edilmiştir. Teorik debi ile $C_{d}$ arasındaki ilişki ise Şekil 7'de verilmektedir. İki değişken arasındaki ilişkiyi göstermek için çeşitli denklem tipleri denenebilmektedir (Burgan ve Aksoy 2018). Doğrusal ve doğrusal olmayan ilişkiler bulunabileceği gibi bu çalışmada teorik debi ve $C_{d}$ arasında doğrusal bir ilişki gözlenmiştir. Şekil üzerinde edilen denklemin performansının değerlendirilmesi amacıyla determinasyon katsayısı hesaplanmış ve $\mathrm{R}^{2}=0.9294$ olarak bire çok bir değer hesaplanmıştır. Bu durum geliştirilen model için elde edilen sonuçların kabul edilebilir mertebede olduğunu göstermektedir.

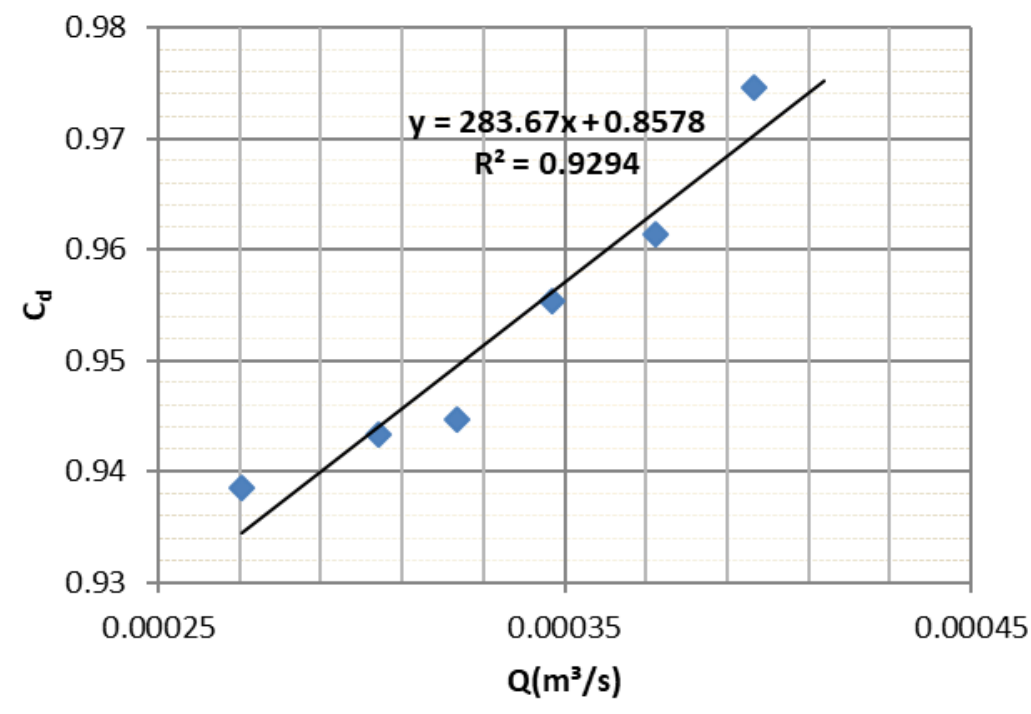

Şekil 7. Teorik debi ile debi düzeltme katsayısı arasındaki doğrusal ilişki.

$\mathrm{Bu}$ deneysel çalışmanın geliştirilerek debi düzeltme katsayısının belirlenmesinde daha hassas sonuçların elde edilmesi mümkündür. $\mathrm{Bu}$ aşamada teorik debinin yanında venturimetre deney düzeneğinde kullanılan diğer değişkenler kullanılabilir. Bu değişkenler, boru pürüzlülüğü ile ilgili rölatif pürüzlülük alanı, rölatif pürüz yüksekliği; akışkan ve akım koşullarıyla ilgili akışkanın özgül ağırlığı, viskozitesi gibi seçilebilecektir. Bu çalışmada teorik debi ve debi düzeltme katsayısı arasında doğrusal bir ilişki bulunmıştur. Diğer değişkenler de dikkate alındığında debi düzeltme katsayısı ve değişkenler arasında doğrusal olmayan bir ilişki elde edilmesi düşünülmektedir. 


\section{Sonuç}

Basınçlı bir boruda akışkan debisinin ölçülmesi her zaman pratik olmamaktadır. Küçük çaplı borularda kararı akım koşulları kısa sürede sağlanabilirken büyük çaplı borularda bu süre saatleri bulabilmektedir. Basınçlı borularda yersel ve sürekli yük kayıplarının olduğu bilinmektedir. Bu kapsamda ölçülen gerçek debi ile teorik debi arasında az da olsa farklılık gözlenecektir. Teorik debinin gerçek debi olarak alınabilmesi amacıyla (11) denklemi ve Şekil 7'de elde edilen debi düzeltme katsayıları kullanılabilecektir.

A-L noktaları arasında yapılan gözlem değerlerine göre A-D noktaları arasındaki yatay mesafenin kısa olması ve kesitin daralması neticesinde meydana gelen yersel yük kaybının küçük olması nedeniyle teorik ve deneysel hesaplanan hızlar arasındaki farkın küçük olduğu gözlenmiştir. Diğer taraftan D-L noktaları arasındaki mesafenin akımın memba kısmındaki A-D bölümüne göre daha uzun olması nedeniyle sürekli yük kaybı daha büyük olacaktır. Sonuç olarak akımın mansap kısmında ölçülen kesitsel ortalama akım hız değerleri teorik olarak hesaplanan değerlerden daha küçük çıkmıştır.

Her koşulda deney yapmanın zorluğu ve elde edilecek gözlemlerin kısıtlı olması nedeniyle ilerideki çalışmalarda bu çalışmadan elde edilen teorik debi ve debi düzeltme katsayısı ilişkisinin kullanılması beklenmektedir. Aynı zamanda basınçlı boruda akımın hız profili ve değerleri boru pürüzlülüğü ile de ilişkili olduğundan akımın Reynolds (Re) sayısı da dikkate alınmalıdır.

\section{Kaynakça}

Akyol, T., Aslan, A., Yüksel, B. (2011). Jeotermal bölgesel 1sıtma sistemlerinin enerji analizlerinde tesisat hataları nedeniyle yaşanan debi ölçüm sorunları. X. Ulusal Tesisat Mühendisliği Kongresi, 13-16 Nisan 2011, İzmir.

Burgan, H. I., Aksoy, H. (2018). Annual flow duration curve model for ungauged basins. Hydrology Research, 49(5), 1684-1695.

Hutton, S. P. (1954). The prediction of Venturi-meter coefficients and their variation with roughness and age. Proceedings of the Institution of Civil Engineers, 3(2), 216-241.

Kocabaş, F., Ülker, Ş. (2004). Tabakalı sıvı ortamında ölçek etkisinin ve su alma borusunun tabandan olan mesafesinin kritik batıklık üzerine etkisi. Türkiye İnşaat Mühendisliği 17. Teknik Kongre ve Sergisi, 15-17 Nisan 2004, Yıldız Teknik Üniversitesi, İstanbul.

Korkmaz, E., Gölcü, M., Kurbanoğlu, C. (2009). Dalgıç pompa performans testlerinde kullanılan yeni teknolojiler. 5. Uluslararası İleri Teknolojiler Sempozyumu (IATS'09), 13-15 Mayıs 2009, Karabük.

Mandavgane, S. (2020). Fun with fluid: An innovative assignment in fluid mechanics. Education for Chemical Engineers, 30, 40-48.

OGEN (2014a). OAG-140 Bernoulli deney seti.

OGEN (2014b). OAG-144 Akış ölçümleri deney seti.

Patel, Y. M., Jain, S. V., Lakhera, V. J. (2020). Thermo-hydraulic performance analysis of a solar air heater roughened with reverse NACA profile ribs. Applied Thermal Engineering, 170, 114940.

Reader-Harris, M. (2015). Venturi Tube Design. Chapter 3 in Orifice Plates and Venturi Tubes, Springer, 77-96.

Steven, R. N. (2002). Wet gas metering with a horizontally mounted Venturi meter. Flow Measurement and Instrumentation, 12, 361372.

Swamee, P. K. (2005). Discharge equations for venturimeter and orificemeter. Journal of Hydraulic Research, 43(4), 417-420.

Wagoner, G. W., Livingston, A. E. (1928). Application of the venturi meter to measurement of blood flow in vessels. Journal of Pharmacology and Experimental Therapeutics, 32(3), 171-180.

Wang, J., Xu, Y., Zhang, T., Wu, H., Wang, H., Huo, X. (2020). A pressure drop model for the annular-mist flow in vertical Venturi. Journal of Natural Gas Science and Engineering, 76, 103168.

Xu, L., Zhou, W., Li, X., Wang, M. (2011). Wet-gas flow modeling for the straight section of throat-extended venturi meter. IEEE Transactions on Instrumentation and Measurement, 60(6), 2011.

Yeşilmen, B., Göğüş, M. (2004). Su jeti pompası ve dip tarama problemlerine uygulanması. Türkiye İnşaat Mühendisliği 17. Teknik Kongre ve Sergisi, 15-17 Nisan 2004, Yıldız Teknik Üniversitesi, İstanbul.

Yılancı, A., Atalay, Ö., Koçar, G., Eryaşar, A. (2019). Dinamik test metodu ile bir güneş kollektörünün 1sıl performansının belirlenmesi. Pamukkale Üniversitesi Mühendislik Bilimleri Dergisi, 25(4), 417-422. 